\title{
Artvin Bölgesi Kıyı Balıkçıı̆̆ında Kullanılan Av Araçlarının Yapısal ve Teknik Özelliklerinin Belirlenmesi
}

\author{
Seda KOÇAN ${ }^{1}$ Tuncay YEŞILCCIÇEK ${ }^{2}$ Ferhat KALAYCI ${ }^{2} *$ \\ ${ }^{1}$ Recep Tayyip Erdoğan Üniversitesi Fen Bilimleri Enstitüsü Su Ürünleri Anabilim Dall, 53100, Rize, Türkiye \\ ${ }^{2}$ Recep Tayyip Erdoğan Üniversitesi Su Ürünleri Fakültesi Avlama Teknolojisi Anabilim Dal, 53100, Rize, Türkiye
}

Atıf yapmak için: Koçan, S., Yeşilçicek, T. \& Kalaycı, F. (2021). Artvin Bölgesi Kıyı Balıkçılığında Kullanılan Av Araçlarının Yapısal ve Teknik Özelliklerinin Belirlenmesi. Anadolu Çev. ve Hay. Dergisi, 6(4), 735-741.

How to cite: Koçan, S., Yeşilçicek, T. \& Kalaycı, F. (2021). Determination of Structural and Technical Characteristics of Fishing Gears Used in Coastal Fishing in Artvin Region. J. Anatolian Env. and Anim. Sciences, 6(4), 735-741.

\footnotetext{
(D) : https://orcid.org/0000-0002-4438-8807

(iD): https://orcid.org/0000-0002-3236-8227

(iD): https://orcid.org/0000-0002-3633-3400

*Sorumlu yazar:

Ferhat KALAYCI

Recep Tayyip Erdoğan Üniversitesi, Su

Ürünleri Fakültesi, Avlama Teknolojisi

Anabilim Dal, 53100, Rize, Türkiye.

凶: ferhat.kalayci@erdogan.edu.tr
}

Öz: Bu çalışma, Ekim 2016- Nisan 2017 tarihleri arasında Artvin ili sınırları içerisinde yer alan Hopa Limanı, Limanköy, Esenkıyı, Sugören, Çamlıköy, Kemalpaşa, Hacılar ve Arhavi'de balıkçılarla yüz yüze anketler yapılarak bölgede kullanılan ağlarının yapısal ve teknik özelliklerini belirlemek amacıyla yürütülmüştür. Çalışma sonunda farklı yapı ve donam özelliklerine sahip 15 takım mezgit ağı, 10 takım palamut ağı, 10 takım zargana ağı, 7 takım barbunya ağı, 6 takım kalkan ağı, 5 takım kefal ağı, 4 takım istavrit ağı, 4 takım kötek ağ1, 3 takım voli ağının kullanıldığı tespit edilmiştir. Araştırma sonucunda, bir türün avcılığı için farklı özelliklere sahip uzatma ağlarının kullanıldığı görülmüştür. Kullanılan ağların teknik ve donam özelliklerinin kullanıldıkları lokalitelerin coğrafi yakınlıklarına göre benzerlik gösterdiği belirlenmiştir.

Anahtar kelimeler: Artvin, av araçları, kıyı balıkçılığı, sade ve fanyalı uzatma ağları, teknik özellikler.

\section{Determination of Structural and Technical Characteristics of Fishing Gears Used in Coastal Fishing in Artvin Region}

\section{*Corresponding author:}

Ferhat KALAYCI

Recep Tayyip Erdogan University, Faculty

of Fisheries, Department of Fishing

Technology, 53100, Rize, Turkey

凶: ferhat.kalayci@erdogan.edu.tr

\begin{abstract}
This study was carried out between October 2016 and April 2017 to determine the structural and technical characteristics of the nets used by conducting face to face interviews with boat owners and net equipping fishermen in shelters and boatyards of Hopa Port, Limanköy, Esenkıyı, Sugören, Çamlıköy, Kemalpaşa, Hacılar and Arhavi which are located within the coastal borders of Artvin province. At the end of the study, gill and trammel nets with different structural and equipment characteristics consisting of 15 sets of whiting net, 10 sets of Atlantic bonito net, 10 sets of garfish net, 7 sets of red mullet net, 6 sets of turbot net, 5 sets of mullet net, 4 sets of horse mackerel net, 4 sets of shi drum net and 3 sets of encircling trammel net were determined. As a result of the study, it was seen that nets with different characteristics were used for catching of a species. It was determined that the technical and equipment characteristics of the nets used were similar according to the geographical proximity of the locations.
\end{abstract}

Keywords: Artvin, coastal fishing, fishing gears, gill and trammel nets, technical characteristics. 


\section{GíRiş}

Küçük ölçekli balıkçılık, özellikle gelişmekte olan ülkelerde beslenme, gıda güvenliği, sürdürülebilir geçim kaynakları ve yoksulluğun azaltılmasına önemli bir katkıda bulunmaktadır. Bu önemli katkıya rağmen, küçük ölçekli balıkçılığın sürdürülebilir kalkınmasını kısıtlayan konular tam olarak anlaşılamamıştır (FAO, 2019). Bu alandaki veri eksikliği, çalışan insan sayısı için de geçerlidir. Küçük ölçekli balıkçılığın çeşitliliği ve toplumsal katkıları, kendi hukuk ve yönetişim sistemlerine sahip olduğu henüz yeni yeni belgelenmeye ve kayıt altına alınmaya başlanmıştır (Kolding vd., 2014).

Küçük ölçekli balıkçılık, 12 m'den küçük balıkçı tekneleri ile kıyı alanını av sahası olarak kabul eden, uzatma ağları, paraketa, kaldırma ağları, olta, tuzaklar gibi av araçlarını kullanarak günü birlik avcılık faaliyeti olarak tanımlanmaktadır. Türkiye'de kıyı balıkçılığının yaygın olduğu bölgelere bakıldığında, küçük ölçekli balıkçıların geleneksel yöntemlerle demersal ve pelajik türleri avlamakta olduğu ve ürünlerini yerel pazara sunmakta olduğu görülmektedir (Ünal, 2003).

Herhangi bir balıkçılık sahasındaki av araçlarının teknik yapılarının bilinmesi; balık stoklarının korunması, sürdürülebilir kullanımı ve yönetiminde doğru karar ve politikalar üretilmesi noktasında önemli bir yere sahiptir (Kara, 2004; Samsun \& Emirbuyuran, 2017). Bir bölgede balıkçılık yapan kişilerin ve balıkçı teknelerinin sayısı, av araçları çeşitliliği ve kapasitesi, avlanan türler ve av miktarları, en az avcılığı yapılan türlerin stok bilgileri kadar gerekli ve önemlidir (Tokaç vd., 2007). Balıkçılıkta kullanılan av araçlarının yapısal özellikleri zaman içerisinde değişim gösterebilmektedir. Güncel ağ planlarının kayıt altına alınması hem av araçlarının gelişiminin hem de balık stokların durumunun izlenmesi açısından son derece önem arz etmektedir (Erdem vd., 2019).

Ülkemizde küçük ölçekli balıkçılıkta kullanılan av araçlarının envanter çalıșmalarının ve teknik özelliklerinin belirlenmesi balıkçılık yönetimi açısından hayati öneme haizdir. Bu konuda ülkemizde yapılan çalışmalar kapsadığı alan itibariyle geniş kapsamlı bir kaç çalışma (Doğan vd., 1991; Tokaç vd., 2010; Samsun \& Emirbuyuran, 2017; Erdem vd., 2020) dışında daha ziyade lokal çalışmalar şeklinde yapılmış olup (Akyol \& Ceyhan, 2007a, Akyol \& Ceyhan, 2007b; Ayaz vd., 2008; Akyol vd., 2009; Altınağaç, 2008; Ay, 2012; Ayaz vd., 2012; Ceyhan \& Akyol, 2005; Demirci \& Demirci, 2007; Doyuk, 2006; Kaykaç vd., 2020; Özekinci vd., 2006; Yıldız \& Karakulak, 2010; Yıldız vd., 2012), bu çalışmaların bir araya getirilmesi ve genel anlamda bir değerlendirmenin yapılması gerekmektedir. Bu bağlamda bu çalışma, Doğu Karadeniz Bölgesi'nde yer alan Artvin ili sahil şeridinde, kıyı balıkçıları tarafından yaygın olarak kullanılan av araçlarının tespiti, teknik özelliklerinin belirlenmesi ve ağ planlarının çizilmesi amacıyla gerçekleştirilmiştir.

$\mathrm{Bu}$ tür çalışmalar ülkemiz balıkçılık potansiyelinin ortaya çıkarılması, sonrasında oluşan yönetim stratejilerinin belirlenmesinde önemli bir adım olacaktır. Ayrıca, bu ve benzeri çalışmalar sonucunda elde edilen veriler 1şı̆̆ında ekosisteme daha duyarlı; balık stokları üzerinde daha az olumsuz etkiye sahip aynı tür balıklar için bölgesel küçük farklılıklar dışında standart bir av aracının oluşturulmasının alt yapısının hazırlanmasına da katkı yapması noktasında önem arz etmektedir.

\section{MATERYAL VE METOT}

Bu çalışma, Ekim 2016- Nisan 2017 tarihleri arasında Artvin ili sınırları içerisinde yer alan Hopa Limanı, Limanköy, Esenkıyı, Sugören, Çamlıköy, Kemalpaşa, Hacılar ve Arhavi'de yer alan balıkçı barınak ve çekek yerlerinde bulunan küçük ölçekli balıkçı tekne sahipleri ile yüz yüze görüşülerek yürütülmüştür. Anket çalışmaları, kıyı bölgesinde kullanılan uzatma ağlarının yapısal ve teknik özelliklerini belirlemek amaciyla bölgede aktif avcılık yapan ve ağ donatan balıkçılarla yüz yüze görüşülerek gerçekleştirilmiştir.

Anketler ile hedef tür, av sezonu, av zamanı ve süresi; avcılıkta kullanılan av araçlarının teknik ve donanım özellikleri ile ilgili bilgiler balıcçıların ifadelerine sadık kalınarak veri formlarına işlenerek elde edilmiştir. A ğ planlarının teknik çizimleri FAO, (1975)'e göre MSOffice 10.0 programı kullanılarak gerçekleştirilmiştir.

\section{BULGULAR}

$\mathrm{Bu}$ çalışma sonucunda, araştırma sahasında 15 takım mezgit ağı, 10 takım palamut ağı, 10 takım zargana ağ1, 7 takım barbunya ağ1, 6 takım kalkan ağ1, 5 takım kefal ağı, 4 takım istavrit ağı, 4 takım kötek ağı, 3 takım voli ağı olmak üzere 64 farklı çeşit yapı ve donam özelliklerine sahip uzatma ağlarının kullanıldığı tespit edilmiştir. Elde edilen bulgular sonucunda, bir türün avcılığı için çok sayıda farklı özelliklere sahip uzatma ağlarının kullanıldığı görülmüştür. Kullanılan ağların özellikleri bölgelerin coğrafi yakınlıklarına göre benzerlik göstermektedir. $\mathrm{Bu}$ bölgede kıyı balıkçılığında kullanılan ağların ağ göz açıklıkları değişkenlik göstermekte olup bu çalışmada verilen ağların teknik çizimlerinde balıkçılar tarafından en çok tercih edilen ağ göz açıklıkları verilmiştir.

Artvin kıyı bölgesinde yapılan çalışma sonucunda küçük ölçekli balıkçılıkta, sade uzatma ağı ve fanyalı uzatma ağı olmak üzere 2 farklı çeşit av aracının yaygın olarak kullanıldığı tespit edilmiştir. Sade uzatma ağları toplam 5 farklı hedef balık türü için kullanılmaktadır. 
Bununla birlikte, fanyalı uzatma ağlarının ise 4 hedef balık türü için kullanılmakta olduğu belirlenmiştir.

Tablo 1. Bölgedeki balıkçılık kıyı yapıları (UDHB, 2019).

Table 1. Fishing coastal structures in the region (UDHB, 2019).

\begin{tabular}{lll}
\hline İlçe & Kıyı yapısının ismi & Sınıfı \\
\hline Arhavi & Arhavi & Balıkçı barınağı \\
Arhavi & Arhavi Hacılar & Çekek yeri \\
Hopa & Esenkıyı & Çekek yeri \\
Hopa & Hopa Çamlıköy & Çekek yeri \\
Hopa & Hopa Limanı & Balıkçı barınağı \\
Hopa & Hopa Limanköy & Çekek yeri \\
Hopa & Kemalpaşa & Balıçı̆ barınağı \\
Hopa & Hopa Sugören & Çekek yeri \\
\hline
\end{tabular}

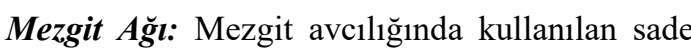
uzatma ağları; 210d/ 0,1 numara PA multifilament materyalden, 16-23 mm göz açıklığında ağlardan meydana gelmekte olup, yoğun olarak 17-18-20 mm göz açıklığındaki ağlar kullanılmaktadır. Ağların yüksekliğine göz sayısı 50 gözdür. Ağın donam faktörü mantar yakada 0,55 , kurşun yakada ise 0,56 'dır (Şekil 1).

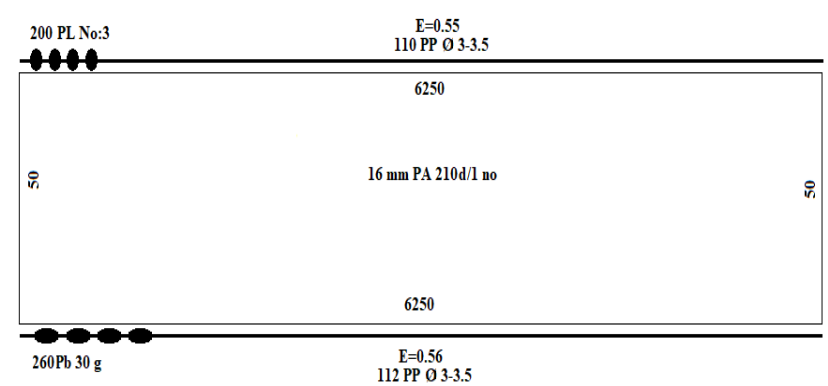

Şekil 1. Mezgit ağının teknik planı.

Figure 1. Technical plan of the whiting gill net.

İstavrit Ă̆g: İstavrit avcılığında kullanılan sade uzatma ağları; 210d/ 0, 1, 2 numara PA multifilament materyalden yapılmış ve 16-17 mm göz açıklığında kullanılmaktadır. Ağların yüksekliğine göz sayısı 150 gözdür. Ağın donam faktörünün mantar ve kurşun yakada 0,55 olduğu tespit edilmiştir (Şekil 2).

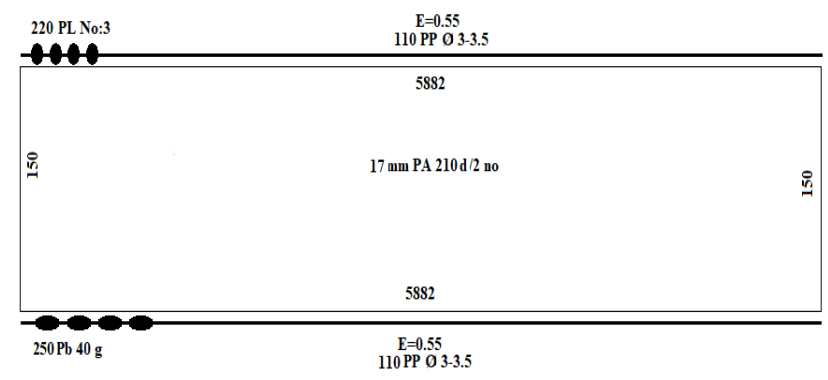

Şekil 2. İstavrit ağının teknik planı.

Figure 2. Technical plan of the horse mackerel gill net.

Zargana A uzatma ağları; $210 \mathrm{~d} / 0,1,2,3$ numara PA multifilament materyalden yapılmış, 10,5-11 mm göz açıklığındaki ağlar kullanılmaktadır. Ağların yüksekliğine göz sayısı 200-500 göz arasında değişmekte olup, genellikle 300-400 göz olarak kullanılmaktadır. Ağın donam faktörünün mantar yakada 0,58 , kurşun yakada ise 0,60 olduğu belirlenmiştir (Şekil 3).

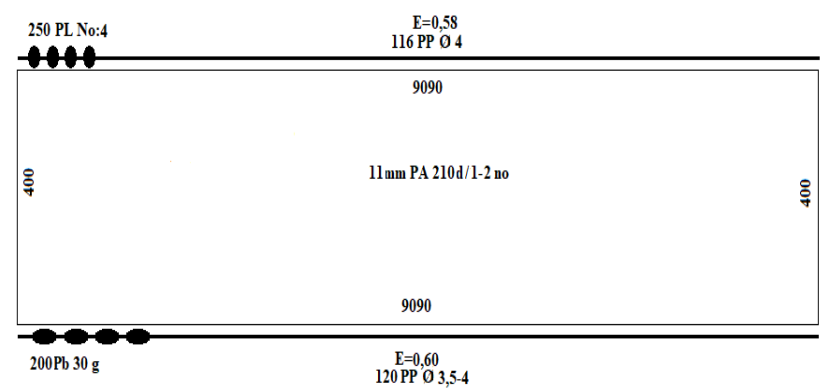

Şekil 3. Zargana ağının teknik planı.

Figure 3. Technical plan of the garfish gill net.

Kalkan Ăğ: Kalkan avcılığında kullanılan sade uzatma ağları; 210d/ 6, 9 numara PA multifilament materyalden, 170, 180, 185, $200 \mathrm{~mm}$ arasındaki göz açıklığındaki ağlar kullanılmaktadır. Ağların yüksekliğine göz sayısı 6,5-9,5 göz arasında değişmekte olup genellikle 7-7,5 göz olarak kullanılmaktadır. Ağın donam faktörü mantar yakada 0,36 ve kurşun yakada ise 0,38 olduğu belirlenmiştir (Şekil 4).

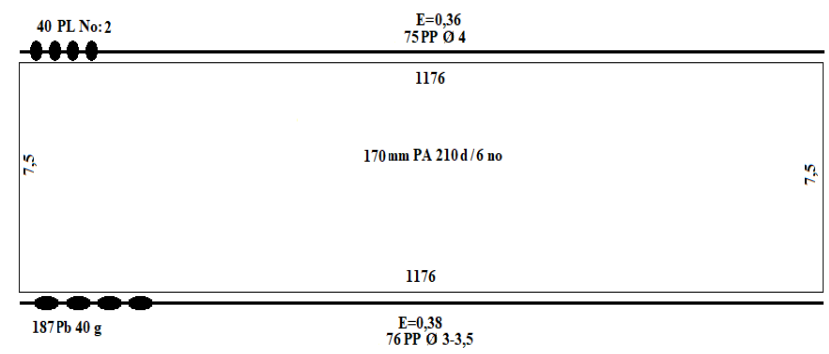

Şekil 4. Kalkan ağının teknik planı.

Figure 4. Technical plan of the turbot gill net.

Palamut A $\breve{g}$ l: Palamut avcılığında kullanılan sade uzatma ağları; 210d/ 2, 3 numara PA multifilament materyalden, 32-42 mm göz açıklığındaki ağlardan meydana gelmekte olup, yoğun olarak 36-38-40-42 mm göz açıklığındaki ağlar kullanılmaktadır. Ağların yüksekliğine göz sayısı 100-600 göz arasında değişmektedir. Ağın donam faktörünün mantar yakada 0,55 olduğu tespit edilmiştir (Şekil 5).

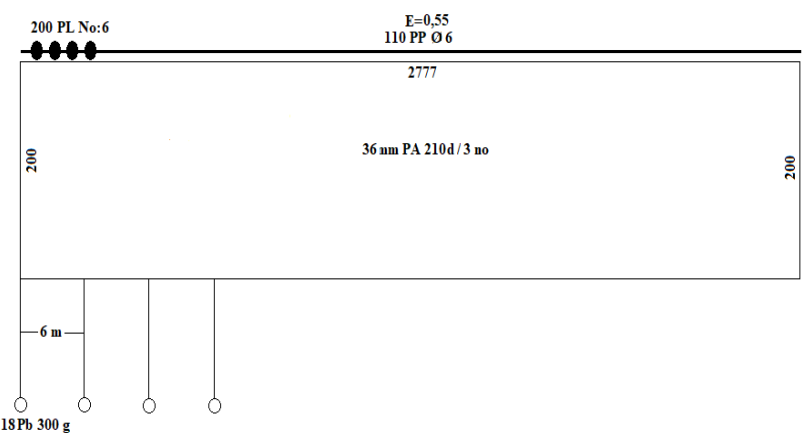

Şekil 5. Palamut ağının teknik planı.

Figure 5. Technical plan of the Atlantic bonito gill net. 
Barbunya Ă̆g: Barbunya avcılığında kullanılan uzatma ağları; tor ăg $210 \mathrm{~d} / 0,1$ numara PA materyalden, 17-18 mm göz açıklığındaki ağlardan meydana gelmekte olup, ağların yüksekliğine göz sayısı 70 gözdür. Fanyalar ise $210 \mathrm{~d} / 2-4$ numara ip kalınlıklarında PA materyalden 90, 130 mm göz açıklığındaki ağlardan meydana gelmekte olup, ağların yüksekliğine göz sayısı 8-8,5-9-12-13 göz arasında değişmektedir. Ağın donam faktörünün mantar ve kurşun yakada 0,55 olduğu belirlenmiştir (Şekil 6).

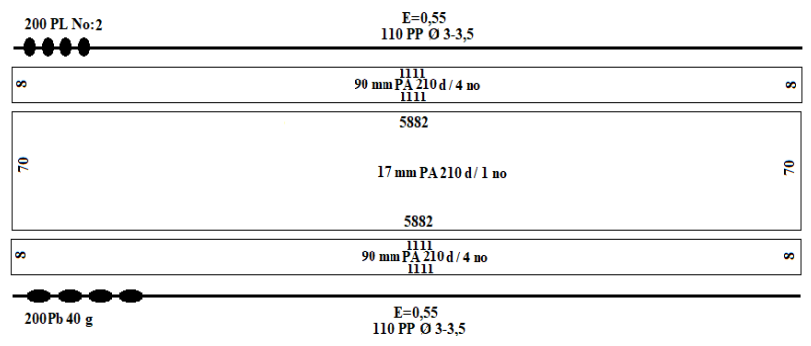

Şekil 6. Barbunya fanyalı ağının teknik planı.

Figure 6. Technical plan of the red mullet trammel net.

Kefal A $\breve{g} \boldsymbol{\imath}:$ Kefal avcılı̆̆ında kullanılan fanyalı uzatma ağlarında tor ağ $210 \mathrm{~d} / 2,3$ numara PA materyalden ve 36-38-40 mm göz açıklığındaki ağlardan meydana gelmekte olup, ağların yüksekliğine göz sayısı 100 gözdür. Fanyalar ise $210 \mathrm{~d} / 3,4,6$ numara ip kalınlıklarında PA materyalden 170, 175, 180 mm göz açıklığındaki ağlardan meydana gelmekte olup, ağların yüksekliğine göz sayısı 13, 14, 16 göz arasında değişmektedir. Ağın donam faktörü 0,50’dir (Şekil 7).

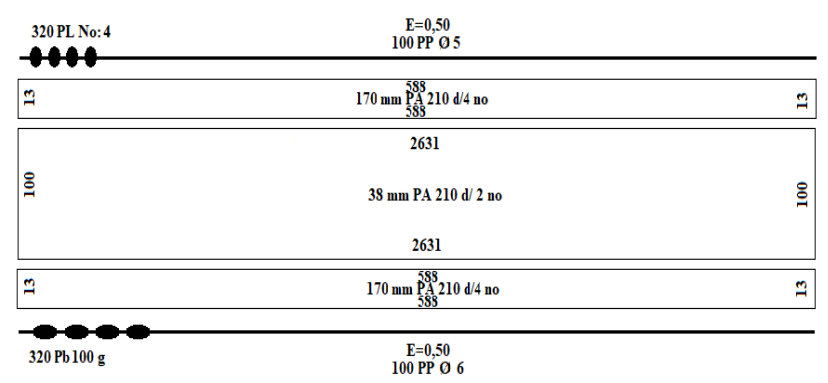

Şekil 7. Kefal fanyalı ağının teknik planı.

Figure 7. Technical plan of the grey mullet trammel net.

Fanyalı Voli Ağı: Fanyalı voli ağlarının tor ağı 210/ 3 numara PA materyalden, 25-30 mm göz açıklığındaki ağlardan meydana gelmekte olup, ağların yüksekliğine göz sayısı 50, 70 gözdür. Fanyalar ise $210 \mathrm{~d} /$ 9 numara PA materyalden $100 \mathrm{~mm}$ göz açıklığındaki ağlardan meydana gelmekte olup, ağların yüksekliğine göz sayıs1 9 gözdür. Ağın donam faktörünün mantar yakada 0,60 , kurşun yakada ise 0,66 olduğu belirlenmiştir (Şekil 8).

Kötek $\boldsymbol{A} \breve{\text { ğl: }}$ Kötek avcılığında kullanılan uzatma ağlar1; tor ağ 210 d/ 2, 3, 9 numara PA materyalden, 40-42$45 \mathrm{~mm}$ göz açıklığındaki ağlardan meydana gelmekte olup, ağların yüksekliğine göz sayısı 50-100 gözdür. Fanyalar ise $210 \mathrm{~d} / 3$ Numara ip kalınlığında PA materyalden $90 \mathrm{~mm}$ göz açıklığındaki ağlardan meydana gelmekte olup, ağların yüksekliğine göz sayısı 9 gözdür. Ağın donam faktörü mantar ve kurşun yakada 0,60 olduğu belirlenmiştir (Şekil 9).

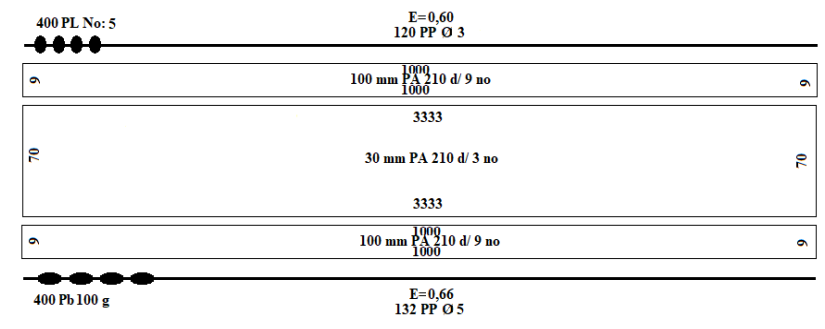

Şekil 8. Fanyalı voli ağının teknik planı

Figure 8. Technical plan of the encircling trammel net.

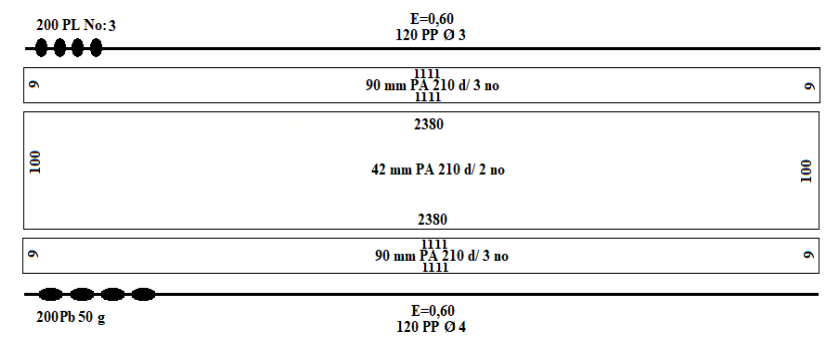

Şekil 9. Fanyalı kötek ağının teknik planı.

Figure 9. Technical plan of the shi drum trammel net.

\section{TARTIŞMA VE SONUÇ}

Bu çalışmada, Artvin ili kıyı balıkçılığında ticari amaçlı su ürünleri avcılığında kullanılan av araçlarının sınıflandırılması yapılarak, FAO standartlarında teknik planları çizilmiş ve çeşitliliği belirlenmiştir. Karadeniz Bölgesi Artvin ili kıyı balıkçılığında sade (galsama) ağlar ve fanyalı (dolanan) ağlar olmak üzere iki çeşit av aracı kullanıldığı tespit edilmiştir. Bu ağların 5 adedinin sade uzatma ağı, 4 adedinin ise fanyalı uzatma ağı olduğu saptanmıştır.

Araştırma sonucunda belirli bir türün avcılığında farklı göz açıklığında ve farklı donam özelliklerine sahip ağların kullanıldığı belirlenmiştir. Çalışma sonucunda bölgede; 15 adet mezgit ağ1, 10 adet palamut ağı, 10 adet zargana ağı, 7 adet barbunya ağı, 6 adet kalkan ağ 1,5 adet kefal ağı, 4 adet istavrit ağı, 4 adet kötek ağı, 3 adet voli ağ1 olmak üzere toplam 64 adet ağ örneklenmiş ve değerlendirilmeye alınmıştır.

Çalışmada elde edilen mezgit ağı, $210 \mathrm{~d} / 0,1$ numara, 16, 17, 18, 20, 22, 23 mm göz açıklığında, 50 göz derinliğinde ve donam faktörü 0,55 olarak tespit edilmiştir. Ay (2012), Rize ilinde yaptığı çalışmada, mezgit ağının $210 \mathrm{~d} / 2$ numara kalınlığında, 16, 17, $18 \mathrm{~mm}$ göz açıklığında, 50 göz derinliğinde, donam faktörünü 0,58 0,60 olarak belirlemiştir. Doyuk (2006), Çanakkale Bölgesi'nde yaptığg çalışmada, mezgit ağını 210 d/2, 3 
numara, $50 \mathrm{~mm}$ göz açıklığında, 100 göz derinliğinde, donam faktörünü 0,50-0,52 olarak belirlemiştir. Yıldız ve Karakulak (2010), İstanbul Bölgesi'nde yaptıkları çalışmada mezgit ağını, $210 \mathrm{~d} / 4$ numara, $50 \mathrm{~mm}$ göz açıklığında, 50, 100 göz derinliğinde, donam faktörünü de 0,63 olarak belirlemişlerdir. Samsun ve Emirbuyuran, (2017), Doğu Karadeniz Bölgesi'nde yaptıkları çalışmada, mezgit ağını 0,14-0,15 mm kalınlığında, 16, 20 mm göz açıklı̆̆ında, donam faktörünü de 0,51 olarak belirlemişlerdir. Altınağaç vd., (2008), Edremit Körfezi'nde yaptıkları çalışmada, mezgit ağını $210 \mathrm{~d} / 2,3$ numara, 23,25 mm göz açıklığında, 100, 120 göz derinliğinde, donam faktörünü de 0,50 olarak belirlemişlerdir.

$\mathrm{Bu}$ çalışmada istavrit ağ $1,210 \mathrm{~d} / 0,1,2$ numara, 16, $17 \mathrm{~mm}$ göz açıklığında, 200 göz derinliğinde, donam faktörü 0,55 olarak tespit edilmiştir. Ay, (2012), Rize ilinde yaptığı çalışmada, istavrit ağını $210 \mathrm{~d} / 2,3$ numara, 16, 17, $18 \mathrm{~mm}$ göz açıklığında, 70, 100 göz yüksekliğinde, donam faktörünü de 0,55-0,58 olarak belirlemiştir. Yıldız ve Karakulak, (2010), İstanbul Bölgesi'nde yaptığı çalışmada, istavrit ağını $210 \mathrm{~d} / 2,3$ numara, 34, $36 \mathrm{~mm}$ göz açıklı̆̆ında, 50, 100 göz derinliğinde, donam faktörünü de 0,68 olarak belirlemişlerdir. Akyol ve Ceyhan (2007a), İzmir Bölgesi'nde yaptıkları çalışmada, istavrit ağını $210 \mathrm{~d} / 3$ numara, $56 \mathrm{~mm}$ göz açıklığında, 120 göz derinliğinde, donam faktörünü de 0,66 olarak belirlemişlerdir.

$\mathrm{Bu}$ çalışmada zargana ağı, $210 \mathrm{~d} / 0,1,3$ numara, 10,5- 11 mm göz açıklığında, 200, 300, 350, 400,500 göz derinliğinde, donam faktörü 0,58 olarak belirlenmiștir. Ay, (2012), Rize ilinde yaptığı çalışmada zargana ağını, 210 d/1, 3 numara, 10,11 mm göz açıklığında, 350, 600 göz derinliğinde, donam faktörünü $0,58-0,60$ olarak belirlemiştir. Doyuk, (2006), Çanakkale bölgesinde yaptı̆̆ 1 çalışmada zargana ağı, $210 \mathrm{~d} / 2$ numara, $25,5 \mathrm{~mm}$ göz genişliğinde, 100 göz derinliğinde, donam faktörünü 0,660,67 olarak belirlemiştir. Samsun ve Emirbuyuran (2017), Doğu Karadeniz Bölgesi'nde yaptıkları çalışmada, zargana ağını $20 \mathrm{~mm}$ göz açılı̆̆ı̆ında, 200 göz derinliğinde, donam faktörünü de 0,60-0,62 olarak belirlemişlerdir.

Kalkan ağ bu çalışmada, $210 \mathrm{~d} / 6,9$ numara, 170 , 180, 185, $200 \mathrm{~mm}$ göz açılıl̆̆ında, 6,5-9,5 göz derinliğinde, donam faktörü 0,36 olarak belirlenmiştir. Ay, (2012), Rize ilinde yaptığı çalışmada, kalkan ağ $210 \mathrm{~d} / 6$ numara, 160, 165, 170, $180 \mathrm{~mm}$ göz açıklığında, 5,5-6,57,5-8,5 göz derinliğinde, donam faktörünü de 0,36-0,38 olarak belirlemiştir. Doyuk, (2006), Çanakkale Bölgesi'nde yaptığı çalışmada, kalkan ağı 210 d/6 numara, $360 \mathrm{~mm}$ göz açıklığında, 6,5-10,5 göz derinliğinde, donam faktörü 0,33-0,34 olarak belirlemiştir. Yıldız ve Karakulak (2010), İstanbul Bölgesi'nde gerçekleştirdikleri çalışmada, kalkan ağı $210 \mathrm{~d} / 6-9$ numara, 320-330 mm göz açıklığında, 7,5 göz derinliğinde, donam faktörünü de 0,27 olarak belirlemişlerdir. Samsun ve Emirbuyuran, (2017), Doğu Karadeniz Bölgesi'nde yaptıkları çalışmada, kalkan ağ $210 \mathrm{~d} / 6$ numara, $340 \mathrm{~mm}$ göz açıklığında, 6,5-9 göz derinliğinde, donam faktörünü de 0,29 olarak belirlemişlerdir.

Palamut ağı bu çalışmada, $210 \mathrm{~d} / 2,3$ numara, 32, 34, 36, 38, 40, $42 \mathrm{~mm}$ göz açıklığında, 100,600 göz derinliğinde, donam faktörü 0,55 olarak tespit dilmiştir. Ay, (2012), Rize ilinde yaptığ çalışmada, palamut ağ 210 d/3, 4 numara, 32, 34, 36, 38, 40 mm göz açıklığında, 100, 200, 300, 400, 500, 600, 700, 800 göz derinliğinde, donam faktörü de 0,58 olarak belirlemiştir. Doyuk, (2006), Çanakkale Bölgesi'nde yaptığı çalışmada, palamut ağı, $210 \mathrm{~d} / 4,6$ numara, 84 mm göz açılı̆ğında, 150, 200 göz derinliğinde, donam faktörü 0,50-0,52 olarak belirlemiş̧ir. Akyol ve Ceyhan, (2007a), İzmir Bölgesi'nde yaptıkları çalışmada, palamut ağ $210 \mathrm{~d} / 4$ numara, $72,76 \mathrm{~mm}$ göz açıklı̆̆ında, 500 göz derinliğinde, donam faktörünü de 0,66 olarak belirlemişlerdir. Akyol ve Ceyhan, (2007b), DatçaBozburun Yarımadası'nda (Ege Denizi) yaptıkları çalışmada, palamut ağ $210 \mathrm{~d} / 4,6$ numara, 68, 72, 80, 84 mm göz açıklığında, 100, 200 göz derinliğinde, donam faktörünü de 0,5 olarak belirlemişlerdir. Ceyhan ve Akyol, (2005), Gökova Körfezi’nde (Ege Denizi) yürüttükleri çalışmada, palamut ağı $210 \mathrm{~d} / 4$ numara, $84 \mathrm{~mm}$ göz açıklı̆̆ında, 150, 200, 250 göz derinliğinde, donam faktörünü de 0,5 olarak belirlemişlerdir.

Barbunya ağı, $210 \mathrm{~d} / 0,1$ numara, 16, 17, $18 \mathrm{~mm}$ göz açıklığında, 70 göz derinliğinde, donam faktörünü 0,55 olarak belirlenmiștir. Ay (2012), Rize ilinde yaptı̆̆ çalışmada, barbunya ağının toru $210 \mathrm{~d} / 1,2$ numara, ağ göz genişliği $16,17,18 \mathrm{~mm}$ ve yüksekliği ise 5-70 göz olduğunu, fan ağı, $210 \mathrm{~d} / 4$ numara, 90, 100, $110 \mathrm{~mm}$ göz genişliğinde 6,5-8,5 göz derinliğinde ve donam faktörünü ise 0,58-0,60 olarak tespit etmiştir. Doyuk (2006), Çanakkale Bölgesi'nde yaptığı çalışmada, barbunya ağı $210 \mathrm{~d} / 2,3$ numara, 40, $44 \mathrm{~mm}$ göz açıklığında, 40 göz derinliğinde, donam faktörü 0,50-0,52 olarak belirlemiş̧ir. Ceyhan ve Akyol (2005), Gökova Körfezi (Ege Denizi)'nde yaptıkları çalışmada, barbunya ağı $210 \mathrm{~d} / 4$ numara, $44 \mathrm{~mm}$ göz açıklı̆̆ında, 45, 50, 60 göz derinliğinde, donam faktörünü de 0,5 olarak belirlemişlerdir. Demirci ve Demirci, (2007), İskenderun Bölgesi'nde yaptıkları çalışmada, barbunya ağı $210 \mathrm{~d} / 4$ numara, 18, 20, $22 \mathrm{~mm}$ göz açıklığında, fanyalar ise 210 d/6 numara kalınlığında, 100, 110 mm göz açıklığında, 4,58 göz derinliğinde, donam faktörünü de 0,67 olarak belirlemişlerdir. Akyol ve Ceyhan (2007b), DatçaBozburun Yarımadası (Ege Denizi)'nda yaptıkları çalışmada, barbunya ağ $210 \mathrm{~d} / 2,3$ numara tor, $210 \mathrm{~d} / 4,6$ numara, 40, 44 mm göz açıklığındaki ağa 220-320 mm göz açıklı̆̆ındaki fanyadan, tor derinliği 40, 45 göz iken 
fanyalar 4,5-5,5 göz derinliğinde, donam faktörünü de 0,66 olarak belirlemişlerdir.

Kefal ağ, 210 d/2, 3 numara 36, 38 ve 40 mm göz açıklığında, fanya ağı gözü açıklığı ise $210 \mathrm{~d} / 3,4,6$ numara, 150, 170, 175, $180 \mathrm{~mm}$ göz açıklığında, 100, 200 göz derinliğinde, donam faktörünü 0,50 olarak tespit edilmiştir. Yıldız ve Karakulak, (2010), İstanbul Bölgesi'nde yürüttükleri çalışmada, kefal ağ $210 \mathrm{~d} / 4$ numara, 56, 64 $\mathrm{mm}$ göz açıklı̆̆ında tor ağ, $210 \mathrm{~d} / 9$ numara, $28 \mathrm{~mm}$, torun derinliği 80 göz iken, fanya derinliği 9 göz, donam faktörü 0,54 olarak belirlemiştir. Ceyhan ve Akyol, (2005), Gökova Körfezi'nde (Ege Denizi) yaptıkları çalışmada kefal ağı, $210 \mathrm{~d} / 3$ numara, 50 göz açıklı̆̆ında, fanyalar ise $210 \mathrm{~d} / 6$ numara, $250 \mathrm{~mm}$ göz açıklı̆̆ında, 13 göz derinliğinde, donam faktörünü de 0,5 olarak belirlemişlerdir. Samsun ve Emirbuyuran, (2017), Doğu Karadeniz Bölgesi'nde yaptıkları çalışmada, kefal ağı 50$60 \mathrm{~mm}$ göz açıklığında, fanya ise $250 \mathrm{~mm}$ göz açıklığında, tor derinliği 75 göz iken fanya derinliği 8 göz, donam faktörü 0,55 olarak belirlenmiştir.

Voli ağ $1,210 \mathrm{~d} / 3$ numara, $25,30 \mathrm{~mm}$ göz açıklı̆̆ında, 50, 70 göz derinliğinde, fanyalar ise $210 \mathrm{~d} / 9$ numara, $100 \mathrm{~mm}$ göz açıklı̆̆ında, 9 göz derinliğinde, donam faktörü 0,60 olarak belirlenmiştir. Ay, (2012), Rize ilinde yaptığı çalışmada, voli ağ $210 \mathrm{~d} / 6,9$ numara, 100, 110, $120 \mathrm{~mm}$ göz açılklı̆ında, 6,5-8,5 göz derinliğinde, donam faktörü 0,63-,0,65 olarak belirlenmiştir. Akyol ve Ceyhan, (2007b), Datça-Bozburun Yarımadası'nda (Ege Denizi) yaptıkları çalışmada iki tip fanyalı voli ağı tespit etmiş olup ilki, $210 \mathrm{~d} / 3,4$ numara, 54, $60 \mathrm{~mm}$ göz açıklığında tor ağ ile, $210 \mathrm{~d} / 4,5,6$ numara, $280,300 \mathrm{~mm}$ göz açıklığında fanya, 70, 100, 120 göz derinliği ile 10 , 16,19 göz derinliğinde, donam faktörünü de 0,5 olarak belirlemişlerdir. Diğer bir versiyonunda ise $210 \mathrm{~d} / 4$ numara, $60 \mathrm{~mm}$ göz açıklığında tor ağ ile $210 \mathrm{~d} / 6$ numara, $280 \mathrm{~mm}$ göz açıklığında, tor ağ 105 göz, fanyada ise 17,5 göz derinliğinde, donam faktörü 0,66 olarak belirlenmişlerdir. Ceyhan ve Akyol, (2005), Gökova Körfezi'nde (Ege Denizi) yapılan çalışmada iki çeşit voli ağı tespit etmiş olup ilki, $210 \mathrm{~d} / 3$ numara, $50,56 \mathrm{~mm}$ göz açıklı̆̆ında, 105, 120 göz, fanyalar ise $210 \mathrm{~d} / 280 \mathrm{~mm}$ göz açıklı̆̆ında, 13,5 göz derinliğinde, donam faktörünü de 0,5 olarak, ikinci voli ağını ise $210 \mathrm{~d} / 2$ numara, $44,50 \mathrm{~mm}$ göz açıklı̆̆ında, 80, 105 göz derinliğinde, fanya $210 \mathrm{~d} / 4$ numara, 250 mm göz açıklığında, 13-13,5 göz derinliğinde, donam faktörünü de 0,5 olarak belirlemişlerdir.

Artvin ili kıyısal bölgede tespit edilen ağlar ile ilgili sonuçları, Rize ili kıyı balıkçılı̆̆ında kullanılan kıyı av araçlarının sonuçları ile paralellik göstermekle birlikte, diğer bölgelerde yapılan çalışmalar ile karşılaştıııldığında önemli farklıkların olduğu görülmektedir. Bu farklılıkların temel nedenlerinin, bölgesel farklılıklar, hedef türlerin boy kompozisyonundaki farklılıklar ve ağ donatan kişilerin kişisel tercihlerine bağlı olduğu düşünülmektedir.

Çalışma sonuçları dikkate alındığında, bölgesel farklılıklar da göz önüne alınarak belirli türlerin avcılığında kullanılan ağların ağ göz açıklıkları, donam özellikleri vb. faktörlerin standart hale getirilmesinin hem bu av araçlarının standardize edilerek daha kolay denetlenebilir ve izlenebilir olmasına, hem bölge ve ülke balıkçılı̆̆ının daha kolay yönetilebilmesine hem de balık stoklarının korunmasına ve sürdürülebilir avcıllı̆ın sağlanmasına katkı sağlayacağı değerlendirilmektedir.

Kıyı balıkçıların kullandıkları ağlar ile ilgili benzer çalışmaların tüm denizlerimizde yapılması ile kıyı balıkçılı̆̆ın doğru bir şekilde yönetilebilmesine katkı sağlayacaktır. $\mathrm{Bu}$ bağlamda ekosistem yaklaşımlı su ürünleri yönetimi noktasında tüm av araçlarının seçiciliklerinin iyileştirilmesi ve hedef dışı (by-catch) oranlarının azaltılması ile ilgili çalışmalar desteklenmeli ve teşvik edilmelidir. Kıyı balıkçılığında kullanılan ağların teknik ve donam özellikleri ile ilgili bilgilerin eksikliğinden dolayı, gerekli ve hayati öneme sahip durumlarda kesin ve doğru sınırlamalar ve önlemler ile ilgili kararların alınabilmesi mümkün olamamaktadır.

Kıyı balıkçılığının mevcut durumun araştırılması ve değerlendirilmesi sürecinde kullanılan ağların teknik ve yapısal özelliklerinin biliniyor olması daha gerçekçi ve geçerli karar alınmasına katkı sağlayacaktır. Küçük ölçekli balıkçılıkla uğraşan balıkçıların dağınık bir görüntüden kurtulması ve kooperatifleşme imkânı ve kabiliyetlerinin artırılması sağlanmalıdır. Bu noktada, balıkçıların ürünlerinin daha yüksek değerden satılması ve gerekli olan av araç ve malzemelerine de daha uygun fiyattan ulaşabilmesinin önü açılmalıdır. Günümüzde av araçlarının, usta çırak ilişkisi veya deneme yanılma şeklinde planlanmasından uzaklaşılarak, konu ile ilgili tarafların birlikte yürüttükleri bilimsel çalışmaların sonucunda, ekosistem ile dost ve sürdürülebilir avcılığı destekleyen av araçlarının yapımı ve kullanımı teşvik edilmelidir.

\section{KAYNAKLAR}

Ceyhan, T. \& Akyol, O. (2005). Gökova Körfezi (Ege Denizi)'nde kullanılan uzatma ağlarının teknik özellikleri. Ege Üniversitesi Su Ürünleri Dergisi, 22(3), 269-272.

Akyol, O., Ceyhan, T. \& Ertostluk, O. (2009). Marmara Adası kıyı balıkçılığı ve balıkçılık kaynakları. Ege Üniversitesi Su Ürünleri Dergisi, 26, 143-148.

Akyol, O. \& Ceyhan, T. (2007a). İzmir Körfezi’nde (Ege Denizi) kullanılan sürüklenen pelajik uzatma ağlarının teknik özellikleri. Ege Üniversitesi $\mathrm{Su}$ Ürünleri Dergisi, 24, 179-183.

Akyol, O. \& Ceyhan, T. (2007b). Datça-Bozburun Yarımadası'nda kullanılan uzatma ağlarının 
teknik özellikleri. Ege Üniversitesi Su Ürünleri Dergisi, 24, 117-120.

Altınağaç, U., Ayaz, A., Özekinci, U. \& Öztekin, A. (2008). Edremit Körfezi dip uzatma ağlarının teknik özellikleri ve yapısal farklılıkları. Journal of FisheriesSciences.com. 2(3), 432-439. DOI: 10.3153/jfscom.mug. 200735

Ay, A. (2012). Rize İli Merkezinde kıyı balıkçılı̆̆ında kullanılan balık yakalama aletlerinin araştırılması. Yüksek Lisans Tezi, Firat Üniversitesi, Fen Bilimleri Enstitüsü, Elazı̆g, Türkiye, $71 \mathrm{~s}$.

Ayaz, A., İşmen, A., Altınağaç, U., Özekinci, U. \& Ayyıldız, H. (2008). Saroz Körfezi dip uzatma ağlarının teknik özellikleri ve yapısal farklılıkları. Journal of FisheriesSciences.com. 2(3), 499-505.

Ayaz, A., Öztekin, A. \& Cengiz, Ö. (2012). Gökçeada ve Bozcaada'da (Kuzey Ege Denizi) kullanılan uzatma ağlarının yapısal özellikleri. Gümüşhane Üniversitesi Fen Bilimleri Enstitüsü Dergisi, 2(2), 104-111.

Ceyhan, T. \& Akyol, O. (2005). Gökova Körfezi (Ege Denizi)'nde kullanılan uzatma ağlarının teknik özellikleri. Ege Üniversitesi Su Ürünleri Dergisi, 22, 269-272.

Demirci, S. \& Demirci, A. (2007). İskenderun Bölgesi'nde kullanılan uzatma ağlarının teknik özellikleri. Türk Sucul Yaşam Dergisi, (3-5) 5-8, 56-363.

Doğan, M., Zengin, M., Şahin, T., Bozali, M. \& Özke, M. (1991). Karadeniz'de av araç ve gereçleri ile avlama teknolojisinin belirlenmesi. Trabzon $\mathrm{Su}$ Ürünleri Merkez Araştırma Enstitüsü, $50 \mathrm{~s}$.

Doyuk, S.A. (2006). Çanakkale Bölgesi'nde kullanılan av araçlarının teknik özelliklerinin belirlenmesi üzerine bir çalışma. Yüksek Lisans Tezi, Çanakkale Onsekiz Mart Üniversitesi, Fen Bilimleri Enstitüsü, Çanakkale, Türkiye, $90 \mathrm{~s}$.

Erdem, Y., Özdemir, S., Özsandıkçı, U. \& Büyükdeveci, F. (2019). Batı Karadeniz'de (Sinop İli) endüstriyel balıkçılıkta kullanılan ağlar ve teknik özellikleri. Turkish Journal of Maritime \& Marine Sciences, 5(2), 74-87.

Erdem, Y., Özdemir, S., Özsandıkçı, U. \& Büyükdeveci, F. (2020). Orta Karadeniz (SinopSamsun) kıyı balıkçılığında kullanılan av araçlarının teknik planları. Marine \& Life Sciences, 2(2), 85-96.

FAO. (1975). Catalogue of small-Scale fishing gears. Food and Agriculture Organization of the United Nations. Fishing News Books Ltd. 191 pp.

FAO. (2019). Food and Agriculture Organization of the United Nations (FAO). Small-scale fisheries. FAO Fisheries and Aquaculture Department. https://www.fao.org/fishery/ssf/en

Hoşsucu, H. (2011). Balıkçılık 1 (Avlama Araçları ve Teknolojisi). Ege Üniversitesi Yayınları, Yayın No: 55, 8. Bask1, $126 \mathrm{~s}$.

Kara, A. (2004). Av araçlarının markalanması ve türkiye'de uygulanabilirliği üzerine öneriler. Ege
Üniversitesi Su Ürünleri Dergisi, 21(1-2), $157-$ 165.

Kaykaç, M.H., Aydın, C. \& Tosunoğlu, Z. (2020). Gillnets and entangling nets fishery in the Gulf of Fethiye. Journal of Anatolian Environmetal \& Animal Sciences, 5(4), 506-515.

Kolding, J., Béné, C. \& Bavinck, M. (2014). Governance for marine fisheries and biodiversity conservation. interaction and coevolution. S. Garcia, J. Rice \& A. Charles (eds) Chapter 22, Small-scale fisheries - importance, vulnerability, and deficient knowledge Wiley-Blackwell, 1-21 pp.

Özekinci, U., Cengiz, U. \& Bütüner, S. (2006). Çanakkale Bölgesi'nde kullanılan uzatma ağlarının donam özellikleri ve balıç̧ıların sorunları. Ege Üniversitesi Su Ürünleri Dergisi, 23, 473-480.

Samsun, S. \& Emirbuyuran, Ö. (2017). Doğu Karadeniz Bölgesi kıyı balıkçılığında kullanılan uzatma ağlarının teknik özellikleri. Ege Üniversitesi Su Ürünleri Dergisi, 34(3), 269-275.

Tokaç, A., Ünal, V., Tosunoğlu, Z., Akyol, O., Özbilgin, H., \& Gökçe, G. (2010). Ege Denizi balıkçılı̆̆ IMEAK Deniz Ticaret Odası İzmir Şubesi Yayınları, 371 s. ISBN: 9789944607476.

Tokaç, A., Ünal, V., Tosunoğlu, Z., Akyol, O., Özbilgin, H. \& Gökçe, G. (2007). Ege Denizi balıkçılığgnın yapısal analizi. Ege Üniversitesi Bilimsel Araştırma Projeleri. 2002/SÜF/006, Bornova, 161 s.

UDHB, (2019). Balıkçılık kıyı yapıları envanteri. Ulaştırma, Denizcilik ve Haberleşme Bakanlığı. Ankara, $8 \mathrm{~s}$.

Ünal, V. (2003). Yarı zamanlı küçük ölçekli balıkçılığın sosyo-ekonomik analizi, Foça (Ege Denizi), Ege Üniversitesi Su Ürünleri Dergisi, 20(1-2), 165 172.

Yıldız, T. \& Karakulak, S.F. (2010). İstanbul kıyı balıkçılığında kullanılan dip uzatma ağlarının teknik özelliklerinin belirlenmesi. Ege Üniversitesi Su Ürünleri Dergisi, 27, 19-24.

Yıldız, T. Gönülal, O. \& Karakulak, S.F. (2012). Gökçeada (Ege Denizi) kıyı balıkçılığında kullanılan av araçları ve teknik özellikleri. İstanbul Üniversitesi Su Ürünleri Dergisi, 27,125 . 